\title{
Parental Stress and Social Support of Caregivers of Children With Cerebral Palsy ${ }^{1}$
}

\author{
Mayara Barbosa Sindeaux Lima \\ Universidade Federal do Pará, \\ Belém-PA, Brazil
}

\author{
Vagner dos Santos Cardoso \\ Universidade Federal do Pará, \\ Belém-PA, Brazil
}

\author{
Simone Souza da Costa Silva \\ Universidade Federal do Pará, \\ Belém-PA, Brazil
}

\begin{abstract}
Stress and social support are relevant variables for understanding the impact of disability on the care relationship. Thus, this study investigates the association between the parental stress index, social support indicators, and the sociodemographic variables of caregivers of children with cerebral palsy in a capital city of the Eastern Amazon. The following instruments were applied to 100 caregivers: the Sociodemographic Inventory, the Gross Motor Function Classification System, the Parenting Stress Index, and the Medical Outcomes Study Social Support Survey. For data analysis, descriptive statistics were used, in addition to techniques of multivariate analysis. It was found that most participants had high parental stress and a high perception of social support. Specific aspects of the perception of social support and sociodemographic indicators were associated with stress. This knowledge favors the design of more assertive interventions because it outlines the aspects of these variables that appear to have a more effective impact on parental stress.
\end{abstract}

Keywords: children, cerebral palsy, caregivers, parental stress index

\section{Estresse Parental e Suporte Social de Cuidadores de Crianças com Paralisia Cerebral}

\begin{abstract}
Resumo: O estresse e o suporte social são variáveis relevantes para se compreender o impacto da deficiência na relação de cuidado. Neste sentido, este estudo investigou a existência de associação entre o índice de estresse parental e indicadores de suporte social e variáveis sociodemográficas de cuidadores de crianças com paralisia cerebral em uma capital da Amazônia Oriental. Cem cuidadores responderam aos instrumentos: Inventário sociodemográfico, Sistema de Classificação da Função Motora Grossa, Índice de Estresse Parental e Medical Outcomes Study Social Support Survey. Para a análise dos dados, utilizou-se a estatística descritiva com técnicas de análises multivariadas. Verificou-se que a maioria dos participantes apresentou um alto estresse parental e a percepção de elevado suporte social. Aspectos específicos da percepção de suporte social e de indicadores sociodemográficos estiveram associados ao estresse. Este conhecimento favorece o planejamento de intervenções mais assertivas, pois delineia que aspectos parecem impactar mais efetivamente no estresse parental.
\end{abstract}

Palavras-chave: crianças, paralisia cerebral, cuidadores, índice de stress parental

\section{Estrés Paternal y Soporte Social de Cuidadores de Niños con Parálisis Cerebral}

\begin{abstract}
Resumen: El estrés y el soporte social son relevantes para comprenderse el impacto de la deficiencia en la relación del cuidado. En ese sentido, investígase la asociación del índice de estrés paternal e indicadores de soporte social y variables sociodemográficas de cuidadores de niños con parálisis cerebral en una capital de Amazonia Oriental. Cien cuidadores contestaron los instrumentos: Inventario sociodemográfico, Sistema de Clasificación de Función Motora Gruesa, Índice de Estrés Paternal y Medical Outcomes Study Social Support Survey. Para el análisis de los datos, se utilizó la estadística descriptiva con técnicas de análisis multivariadas. Verificase que la mayoría de los participantes presentaron alto nível de estrés paternal y alta percepción de soporte social. Aspectos específicos de la percepción de soporte social y de indicadores sociodemográficos estaban asociados al estrés. Este conocimiento favorece la planificación de intervenciones más asertivas, una vez que delinea qué aspectos de estas variables parecen impactar más efectivamente el estrés paternal.
\end{abstract}

Palabras clave: niños, paralísis cerebral, cuidadores, índice de estres parental

The birth of a child involves the addition of a new social role to its parents and can represent the beginning of a new life cycle. This event acquires unique characteristics when the child is disabled, an unexpected and potentially anxiogenic situation (Dantas, Pontes, Assis, \& Collet, 2012).

\footnotetext{
${ }^{1}$ Support: This study was funded by the National Council for Scientific and Technological Development - CNPq, Universal call 2013 (Grant \# 486017/2013-3), and by the Dean of Research and Graduate Studies at the Universidade Federal do Pará.

${ }^{2}$ Correspondence address:

Mayara Barbosa Sindeaux Lima. Av. São Paulo, $\mathrm{n}^{\circ}$ 142, Bairro Belo Horizonte. CEP 68502-380. Marabá-PA, Brazil. E-mail: mayarasindeaux@, unifesspa.edu.br
}

Cerebral palsy is the most common cause of motor impairment in childhood and may be associated with sensory and intellectual disabilities. The term cerebral palsy (CP) encompasses several different clinical conditions that share in common the presence of motor/postural problems due to chronic, non-progressive neurological injury occurring during the development of the central nervous system (Cans, 2000).

The care burden imposed by a disabled child can have negative repercussions on his or her parents' health. Some studies have indicated that, in general, the parents of children with $\mathrm{CP}$ perceive their own health as unsatisfactory, including symptoms of depression, stress, muscle pain, and diminished quality of life (Freitas, Rocha, \& Haase, 2014; Guyard, Fauconnier, Mermet, \& Cans, 2011). 
According to the literature, caregivers of children with CP generally exhibit impairments in physical and mental health; however, there is little agreement regarding the relationship between such impairments and the child's degree of motor deficiency (Al-Gamal \& Long, 2013; Byrne, Hurley, Daly, \& Cunningham, 2010; Ribeiro, Sousa, Vandenberghe, $\&$ Porto, 2014). This lack of agreement suggests that other variables in addition to those directly related to the child and his or her disability influence the mutual adjustment between parents and children (Dantas et al., 2012; Glenn, Cunningham, Poole, Reeves, \& Weindling, 2009; Guyard et al., 2011).

According to Carona, Crespo, and Canavarro (2013), theories that seek to understand the family's adaptation to disability or chronic diseases in childhood consider several variables, such as family functioning, social support, and parental stress, within the context of the child's care, suggesting the relevance of these variables in the process of coping with disability.

In adequate levels, parental stress is a motivational factor that drives parents to use resources that help them to parent. Parental stress is the result of the parents' self-assessment of their commitment to their idealized parental role, which includes their goals and expectations for themselves and the child, in addition to the resources that they perceive as available to them for the performance of this role (Abidin, 1992).

High levels of parental stress have been associated with impaired mental health, poorer quality of life, and dissatisfaction with the social support perceived by the parents or primary caregivers of children with CP (Al-Gamal \& Long, 2013; Guyard et al., 2011). Social support seems to both prevent and attenuate stressful situations, and its absence can lead to feelings of abandonment, sadness, and anger, which can have negative repercussions for the family's experience in the face of disability (Polita \& Tacla, 2014; Whittingham, Wee, Sanders, \& Boyd, 2013).

Social support refers to the material and psychological resources that a person deems to be available to him or her via his or her interpersonal relationships. In turn, satisfaction with social support concerns the perception that such resources and the bonds with the members of the support network are adequate to the existing demands (Rodriguez \& Cohen, 1998). Pfeifer et al. (2014) argue that perceived social support seems to exert more influence on the adaptation to stressful experiences than the social support that is actually received or the number of members of the support network.

The relevance of social support for families of children with $\mathrm{CP}$ was noted in a literature review conducted by Oliveira and Dounis (2012). These authors performed a search for Brazilian articles published from 2000 to 2010, and only 18 studies met the selection criteria. The results indicated that quality of life tended to be poorer and that the levels of stress and depression tended to be higher among the caregivers of children with $\mathrm{CP}$ who had an incipient family and professional support network compared to those who had a fully developed network.

The aforementioned considerations lead to the conclusion that the social support perceived by caregivers of children with $\mathrm{CP}$ is an important variable for understanding the impact of the disability on the care relationship and parental stress. An investigation of the association between parental stress and perceived social support and sociodemographic aspects may improve the knowledge on the processes of caregiver development and provide grounds for the formulation of public policies and more effective services that target this population.

In this context, the aim of the present study is to describe sociodemographic, parental stress and perceived social support indicators for primary caregivers of children with $\mathrm{CP}$ from a capital city in the Eastern Amazon and to investigate whether these variables are associated.

\section{Method}

\section{Participants}

The sample comprised 100 primary caregivers of children with $\mathrm{CP}$ from one to 12 years of age cared for at a university hospital in Belém, the capital of the state of Pará, in 2014. A total of 98 participants were female. Nonprobabilistic and convenience sampling was used.

The criteria for participant selection were as follows: being of legal age and a relative or guardian of a child with $\mathrm{CP}$ from one to 12 years of age; being the child's primary caregiver, defined as the person charged with providing informal child care most of the day for at least one year; having the sufficient verbal and/or writing skills to complete the instruments; and the $\mathrm{CP}$ child cared for should not have any autism spectrum disorder, genetic syndromes, or mental disorders as comorbidities.

\section{Instruments}

Sociodemographic Inventory (SDI). This instrument was elaborated by the investigators to collect sociodemographic data relating to both caregivers and children with CP. It comprises objective questions about the caregivers' gender, age, educational level, family income and composition, marital status and occupation, and the clinical manifestations of the child with CP.

Gross Motor Function Classification System - GMFCS. This instrument makes it possible to classify the gross motor function of children with CP into five levels of severity based on their age and ability to self-initiate movements related to sitting and walking. An increase in level indicates greater impairment; thus, Level I is the mildest (no restrictions but with limitations in some movements), and Level $\mathrm{V}$ is the most severe (the child is transported in a wheelchair and exhibits many limitations even with the use of assistive technology) (Russell, Rosenbaum, Avery, \& Lane, 2011). The crosscultural adaptation of the GMFCS for Brazil was performed by Hiratuka, Matsukura, and Pfeifer (2010). The results indicated semantic and conceptual equivalence, sufficient inter-rater reliability, excellent construct correlation, and internal consistency, with an intraclass correlation coefficient of .945 and a Cronbach's alpha of .972 .

Parenting Stress Index - PSI (Abidin, 1995). This instrument measures parents' self-perceived stress. The short 
form comprises 36 items to be answered on a Likert scale ranging from 1 (strongly agree) to 5 (strongly disagree). The present study used the PSI-Short Form/SF adaptation described by Minetto (2010). Based on a sample comprising 120 respondents, the author found that the reliability of the instrument was satisfactory, with a Cronbach's alpha ranging from .85 to .86 . The PSI comprises three 12 -item domains: (a) Parental Distress, which assesses parents' perceptions of their own feelings as fathers/mothers; (b) the Parent-Child Dysfunctional Interaction, which investigates whether the parents' perceptions of their child agree with their expectations, in addition to whether their interactions with their child reinforce their role as fathers/ mothers; and (c) the Difficult Child, which concerns several behavioral aspects of children that define them as easy or difficult to handle. In the present study, domains a, $\mathrm{b}$, and c exhibited satisfactory internal consistency, with a Cronbach's alpha of $.82, .89$, and .85 , respectively. The intensity of parental stress on the global scale and relative to each particular domain may be categorized as Clinical Stress and Subclinical Stress.

Medical Outcomes Study Social Support Survey - MOSSS (Sherbourne \& Stewart, 1991). This scale, adapted for the Brazilian population by Griep (2003), measures structural and functional social support. It comprises 20 questions, 19 of which address perceived social support and are the questions used in the present study. The questions begin with the following phrase: "If you needed it, how often is someone available?" The respondents are required to mark their answers on a Likert scale ranging from none of the time (1) to all of the time (5). This instrument exhibited satisfactory reliability and validity indicators both in its original version (test-retest: .78; internal consistency: .91 and higher) and in Griep's (2003) study, with a Cronbach's alpha higher than .83 and the measures of concordance, including the kappa and weighted kappa statistics, higher than .70 .

Factor analysis (FA), a multivariate statistical technique, was applied to the instruments with Likert scales, i.e., the PSI and the MOS-SS, to reduce the variables to smaller linear combinations (dimensions), albeit with greater explanatory power to validate the instruments. First, the reliability of the items was assessed by using Cronbach's alpha; the result was .75 for the PSI and .92 for the MOS-SS, which indicates that these scales are consistent. Next, the viability of FA was assessed based on the following: visual inspection of the correlation matrix, which detected a substantial number of correlations with values over .30; application of Bartlett's test of sphericity ( $p=.000$ for the PSI, $p=.001$ for the MOS-SS); the Kaiser-Meyer-Olkin test, which yielded results of .75 for the PSI and .82 for the MOS-SS; and Measure of Sampling Adequacy, the values of which were higher than .50 for both instruments. These analyses indicated that FA was viable.

Next, FA was performed by means of the principal components mathematical method and factor extraction via varimax orthogonal rotation. The criteria adopted to select the number of factors to be extracted were the latent root criterion (an eigenvalue greater than 1) and the percentage of explained variance (the sum of explained variance $\geq .70$ ).
In the case of the PSI, a four-factor model with nine items was sufficient to represent the initial covariance structure, explaining $72.85 \%$ of the total variability of the original items. Relative to the MOS-SS, a four-factor model with 14 items was sufficient to represent the initial covariance structure, explaining $70.6 \%$ of the total variability of the original items.

The internal consistency of the items after FA was analyzed by using Cronbach's alpha; the results indicated satisfactory levels of adequacy of the measure to the investigated population for both the PSI, with values varying from .70 to .77 , and the MOS-SS, with values ranging from .75 to .86 .

\section{Procedure}

Data collection. The present study was a crosssectional exploratory/descriptive study that was conducted at a university hospital in the city of Belém, the capital of the state of Pará, in the Eastern Amazon. This institution is a reference for the multi-professional care of children with atypical development, who are provided neurological, orthopedic, and physical therapy care, among other services, through a specific program.

Initially, the objective of the study was to cover the full population of primary caregivers of children with CP cared for within the context of the aforementioned program in 2014. However, the number of patients could not be established. For this reason, the investigators applied the following procedure to recruit the study sample: they visited the program waiting room and invited the primary caregivers of children with $\mathrm{CP}$ who were encountered to participate in the study. Sample saturation was achieved eight months after the start of data collection, with the frequency of new participants gradually declining until further attempts revealed that the individuals encountered had already been included in the study database.

The caregivers who met the selection/exclusion criteria and who agreed to participate signed an informed consent form; subsequently, they individually completed the instruments applied by one of the investigators in the waiting room. The level of motor impairment according to the GMFCS was established based on direct observation of the child.

Data analysis. The data were entered into the Statistical Package for the Social Sciences (SPSS 20.0 for Windows) software to perform statistical analysis by using the tools that it provides.

The procedure for PSI correction followed Minetto's (2010) instructions; the participants' scores on all of the PSI items were added, resulting in the Parenting Stress Total score; the score of each PSI domain was similarly calculated, i.e., by adding the scores on the corresponding items. Score inversion was performed for items that required it.

Next, the Parenting Stress Total score and the scores of each individual domain were compared to a percentile table; based on this procedure, they were categorized as Clinical Stress when they fell into the 90th percentile or above and as Subclinical Stress when they fell under the 90th percentile.

For the MOS-SS, the scores corresponding to the four factors suggested by factor analysis were calculated; these 
factors were named Affectionate Support, Emotional Support and Positive Social Interaction, Informational Support, and Tangible Support. Due to the variation in the number of items allocated to each factor, the scores were standardized, as suggested by Griep (2003): the sum of the scores in each factor was divided by the corresponding maximum possible score; for example, given that the responses were distributed across a five-point scale, the maximum possible score of a two-item factor was 10 . The results were then multiplied by 100 to convert them to percentages. The same procedure was performed to calculate the scale total percentage score. Given that no cutoff points are available for the MOS-SS, it is considered that the closer to $100 \%$ that the percentage obtained is, the better the perceived social support.

Because the MOS-SS does not make it possible to categorize the respondents, the Perceived Social Support Index (MOS-SS Index) was calculated based on a linear combination of the factor scores and the proportion of variance explained by each factor. The resulting indexes were distributed across two equal intervals (.344|-- .654 and .655|-- .748).

Next, the data obtained through the SDI, GMFCS, MOSSS, and PSI were analyzed by using descriptive statistics (frequency, mean, and standard deviation). This step made it possible to establish the viability of statistical analyses that detect association between variables.

Total Parenting Stress (categorized as Clinical Stress and Subclinical Stress) was tested against the MOS-SS Index, the GMFCS, and the sociodemographic variables (family income, marital status, occupation, and the presence of health problems in the child related to $\mathrm{CP}$ or appearing as comorbidities). Next, the presence of association between the PSI items and the MOS-SS Index and between the PSI items and MOS-SS items was investigated. All of the association analyses were performed by using the non-parametric chisquare $\left(\chi^{2}\right)$ test at the significance level of $5 \%$. Application of parametric tests, such as Pearson's correlation coefficient, was unviable due to the large number of missing responses in several categories of the variables.

The Total Parenting Stress data with significant results on the $\chi^{2}$ test were subjected to correspondence analysis, a multivariate statistical technique, to investigate the relationship between the variables and to visualize the association between the frequencies of the variable categories (Infantosi, Costa, \& Almeida, 2014). First, the beta $(\beta)$ criterion test was performed to investigate the dependence between the categories of the variables; the variables were considered to be dependent when $\beta>3$. Next, the total sum of the percentage of inertia of dimensions 1 (Total Parenting Stress) and 2 (sociodemographic variables) was analyzed; its value should be greater than $70 \%$. The last step consisted of estimating the confidence coefficient $(\gamma)$ by calculating the standardized residuals; relationships were considered to be significant when $\gamma \geq 70 \%$.

\section{Ethical Considerations}

The present study was assessed and approved by the Ethics Committee of the Health Sciences Institute of the
Universidade Federal do Pará (Protocol n. 473.140). The study complied with the National Health Council/Health Ministry Resolution n. 466, December 12, 2012. Individuals who met the inclusion criteria were invited to participate in the study; those who agreed were asked to sign an informed consent form. At that time, they were informed about the confidentiality of information, the study aims, and the possible risks and benefits associated with participation in the study.

\section{Results}

The sample mostly comprised mothers of children with CP (91\%); the remaining participants were grandmothers (6\%), fathers $(2 \%)$, and one stepmother $(1 \%)$. Their mean age was 33.3 years old $(\operatorname{Min}=20, \operatorname{Max}=55, S D=8.3)$. The family income was up to twice the equivalent of the minimum wage for most of the sample (81\%), and in $49 \%$ of the sample, the family had five or more members. Most participants were unemployed; $80 \%$ reported being homemakers; $66 \%$ were in a steady relationship (married/civil union); and $25 \%$ reported being the single caregiver of the child. The educational level of the sample was low: only $41 \%$ of the participants had completed secondary education. Almost half of the participants (45\%) resided in towns outside the Belém Metropolitan Area.

Approximately $53.5 \%$ of the children with CP cared for by the participants were of school age; their mean age was six years old $(\operatorname{Min}=1, \operatorname{Max}=12, S D=3)$. Most of the children $(63 \%)$ were classified under the most severe GMFCS levels of motor impairment, i.e., IV and V.

Regarding the PSI, the mean Parenting Stress Total score was $88.4(S D=15.2) ; 42 \%$ of the participants were classified as having Clinical Stress on the global scale, given that their scores were 91 or higher, i.e., corresponding to the 90th percentile or over.

Analysis of the PSI domains of Parental Distress, the Difficult Child, and the Parent-Child Dysfunctional Interaction showed that the latter was the main source of stress; $45 \%$ of the participants were classified as having Clinical Stress. The scores of 28 participants fell above the 95th percentile. Parental Distress had the second highest proportion of participants classified as having Clinical Stress (33\%). Finally, 22\% of the participants were classified as having Clinical Stress based on the scores corresponding to the Difficult Child domain.

Regarding the perception of social support indicated that the participants were satisfied with the support they received, with the percentage score on the MOS-SS of $81 \%$. The Affectionate Support factor received the highest score, 92\%, followed by Tangible Support, $82 \%$. The lowest scores were exhibited by the factors of Emotional Support and Positive Social Interaction and Informational Support, at $76 \%$ for both.

Some MOS-SS items exhibited a considerable degree of concordance among the participants: at least $85 \%$ answered that someone is available "all of the time" or "most of the time" to "love and make you feel wanted", "show you love and affection", and "hug you".

For a portion of the participants, some social support aspects were practically inexistent, given that they answered 
that someone is available "none of the time" or "little of the time" to "get together with for relaxation" (26\%), "understand your problems" (24\%), "confide in or talk to about yourself or your problems" $(23 \%)$, or "share your most private worries and fears with" (22\%).

The results of the analyses that investigated the association between Total Parenting Stress and the MOS-SS Index showed that these variables did not exhibit a relationship of dependence in the studied sample, given that the p-value found through application of the chi-square test was more than .05. Nevertheless, crossing the PSI items with the MOSSS Index revealed that the latter seemed to be influenced by PSI items 11 and 34: "I am not as interested in people as I used to be" ( $p=.023)$ and "My child does a few things that bother me a great deal" ( $p=.006)$, respectively.

The $\chi^{2}$ test allowed detecting that some PSI and MOS-SS items were significantly associated. The results suggest that the response to the statement "I am not as interested in people as I used to be" (PSI item 11) influenced the respondents' perception of having someone available to "take you to the doctor", "count on to listen to you when you need to talk", "confide in or talk to about yourself or your problems", "understand your problems", "do things with to help you get your mind off things", and "get together with for relaxation" (MOS-SS items 2, 8, 9, 11, 17, and 18). PSI item 29 ("My child reacts very strongly when something happens that my child doesn't like") seemed to influence the respondents' perception of having someone available to "help you if are confined to bed", "take you to the doctor" and "offer advice you really want" (MOS-SS items 1, 2, and 14).

Regarding the association between Total Parenting Stress and the sociodemographic characteristics, significance was found for marital status ( $p=.04)$, caregivers' educational level $(p=.022)$, and presence of health problems in the child related to CP or appearing as comorbidities $(p=.000)$. No association was found for family income, caregivers' occupation, or the GMFCS.

The multivariate statistical technique of correspondence analysis could be applied between the categories of Total Parenting Stress (Clinical Stress and Subclinical Stress) and the sociodemographic characteristics, which were found to be associated, given that they met the technique criteria: the beta $(\beta>3)$, percentage of inertia $(\geq 70 \%)$, and confidence coefficient $(\gamma \geq 90 \%)$.

The sociodemographic variables were classified as follows: a) educational level $(\beta=3.92)$, subdivided into Incomplete Primary Education (IPE), Complete Primary Education (CPE), and Complete Secondary Education (CSE); b) marital status $(\beta=7.26)$, subdivided into With spouse, when married or in a civil union, and Without spouse, when single or divorced; and c) health problems in the child related to $\mathrm{CP}$ or appearing as comorbidities $(\beta=12.93)$, subdivided into Presence of Problems (PP) and Absence of Problems (AP).

The perceptual map resulting from correspondence analysis is depicted in Figure 1.

The analysis revealed two participant profiles: (a) caregivers with Clinical Stress, in general, had a low educational level and were not in a stable relationship,
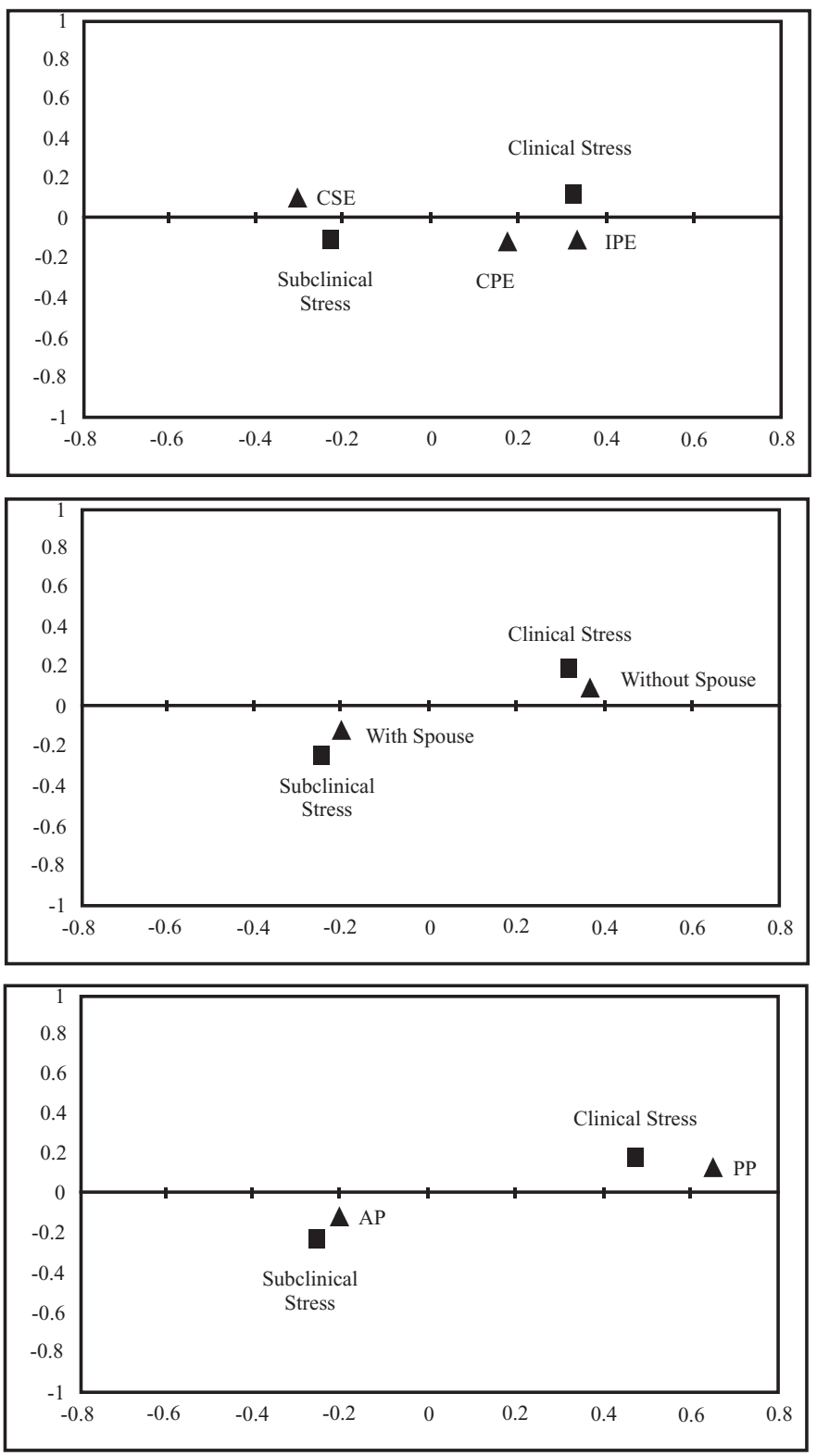

Figure 1. Perceptual maps resulting from correspondence analysis between Total Parenting Stress (Clinical Stress and Subclinical Stress) and the following sociodemographic variables: educational level (CSE - Complete Secondary Education, CPE - Complete Primary Education, and IPE - Incomplete Primary Education); caregivers' marital status (With Spouse and Without Spouse); and the presence of health problems in the child related to $\mathrm{CP}$ or appearing as comorbidities (AP - Absence of Problems and PP Presence of Problems). Source: raw data.

and the child under their care had other health problems or dysfunctions in addition to motor disorders; and (b) caregivers with Subclinical Stress, in general, had completed secondary education, were married or in a civil union, and provided care to children without health problems related to $\mathrm{CP}$ or appearing as comorbidities.

\section{Discussion}

The caregivers' socioeconomic profile suggests that most of them lived under conditions of social vulnerability. One further aspect that warrants attention is that almost 
half of the participants lived in towns outside the Belém Metropolitan Area, which implies the need to travel, with consequent financial, physical, and/or emotional costs.

Financial difficulties and a low educational level may be hindrances to a more effective social integration of the child and his or her family and may restrict access to only certain healthcare services and the purchasing of equipment to facilitate accessibility and communication (Ribeiro et al., 2014). This situation is even more serious because we found that more than half of the children had severe motor impairment.

Public health strategies and the actions of professionals can attenuate the impacts of social vulnerabilities on the families of children with CP. One of the mechanisms for such attenuation to occur is to make available social support and orientation on how to access formal support networks. In this manner, family resources are boosted, and other resources become accessible (Ribeiro et al., 2014).

The children's degree of motor impairment seemed to have little influence on parental stress, given that these two variables were not associated. There is little agreement in the literature regarding the relationship between the child's motor functioning and the parents' stress and/or health (Byrne et al., 2010; Guyard et al., 2011; Ribeiro et al., 2014). Byrne et al. (2010) and Ribeiro et al. (2014) find results similar to those of the present study and argue that these findings reinforce the idea that the impairments to health and quality of life seem to depend more on how the child's family copes with adverse situations and organizes itself as a system, in addition to the resources available to it, than on the child's disability itself.

The considerations above are even more worrisome in the case of the investigated sample, given the high levels of parental stress it exhibited, agreeing with the findings reported by Dang et al. (2015) and Ribeiro et al. (2014). Almost half of the participants have stress levels requiring clinical evaluation and probably need therapy assistance.

Regarding the PSI domains, stress was detected more often in the Parent-Child Dysfunctional Interaction domain, which concerns the caregivers' expectations for the child to meet the idealized image of him/her that they have built (Ribeiro et al., 2014). In this regard, it may be assumed that the greater the discrepancy is between the child's skills as perceived by the caregiver and those that the caregiver would like the child to have, the greater the difficulty of the caregiver to accept the child's disability.

According to Minetto (2010), high scores in this domain may be associated with the idea that the child is a negative element in the life of the caregiver, who may feel disappointed or rejected/maltreated by the child. This domain was described as the domain most directly associated with the phenomenon of neglect. Scores above the 95th percentile, which were found in more than one-fourth of the participants in the present study, "suggest the possibility of abuse, neglect, rejection or physical injury episodes derived from feelings of frustration" (Minetto, 2010, p. 67).

The domain of Parental Distress ranked second in frequency of caregivers with clinical stress. This domain investigates the presence of feelings of incompetence in the performance of the parental role, depression, and whether the child's demands make his/her parents suffer and restrict their social participation (Minetto, 2010). Ribeiro et al. (2014) also found a high percentage of clinical stress in the Parental Distress domain.

The changes in the caregivers' life plan and the high levels of parental investment demanded by the child's disability, combined with low self-esteem and financial difficulties, may cause stress (Dantas et al., 2012; Polita \& Tacla, 2014). In addition, these factors favor the development of feelings of being incompetent to provide support to the child, which negatively affects the parents' satisfaction with their parental role (Ribeiro et al., 2014).

If parental stress was a risk factor for the caregivers, and consequently also for the family system, then the perceived social support behaved as a protective factor, given that the percentage scores on the MOS-SS were high; this finding agrees with that reported by Pfeifer et al. (2014). However, although the participants reported being satisfied with the social support they received, it did not seem to sufficient to reduce the level of parental stress.

The high percentage score exhibited by the Affectionate Support factor suggests that the participants feel loved whenever they need to. However, Lima, Afonso, and Silva (2015) observe that having someone available to provide this type of support does not mean that the demands for affection and understanding are actually met because the person in question may not always be the individual who the caregiver would like, that is, generally his or her spouse.

The social support provided by spouses seems to be an important element in the family dynamics of the participants because the lack of a spouse was associated with clinical stress. In Glenn et al. (2009), low spousal support and poor family cohesion are shown to favor the occurrence of higher levels of maternal parenting stress.

Although perceived social support was high in all four scale factors, item analysis showed that a considerable proportion of the participants (approximately 23\%) did not have anyone available to share private issues with and to provide emotional comfort.

The data above make it possible to raise several hypotheses: (a) caregivers may avoid talking about their problems not to overload the members of their support network, given that the latter already provide other types of support; (b) practical issues may be considered more urgent or a more likely reason to ask for help at the expense of emotional issues; (c) caregivers may have difficulty organizing emotion-related thinking and also have poor verbal ability to express their intimacy due to their low educational level; (d) sharing one's intimacy may be perceived as an aversive stimulus because others may lack empathy, call into question the truth of what they are told, or make negative judgments, such as considering the caregivers to be incompetent in the performance of their social roles; (e) the social support network may have difficulties of its own in making this type of support available, either to avoid subjects likely to generate negative emotions or because it fails to detect the existence of, or underestimates, this particular demand.

According to Whittingham et al. (2013), the excessive avoidance of contact with painful emotions, sensations, and 
memories favors the development of a maladjusted behavioral repertoire and psychological problems among parents of children with CP. In this regard, frequent attempts to control the form of, frequency of, or sensitivity to private events associated with sadness or anguish impair psychological well-being.

The lack of association between the Total Parenting Stress and Perceived Social Support indicators is considered an uncommon result in the literature (Al-Gamal \& Long, 2013; Guyard et al., 2011). This finding may be explained by the constructs that ground the MOS-SS, given that this instrument investigates the respondents' perception of the availability of various types of support without considering the specific demands associated with parenthood. It may be assumed that the caregivers were satisfied with the types of support that they were asked to evaluate. However, an important type of support demand, such as sharing carerelated tasks, may not have been adequately investigated and may have impaired the analysis of the impact of perceived social support on parental stress.

Nevertheless, the MOS-SS provided data relevant for the understanding of parental stress. For instance, it showed that the perception of disruptive behaviors in the child had an impact on the perception of social support. The behavioral/ emotional problems and cognitive impairments of children with CP have been associated with parental stress and were even included in the predictive model of stress (Freitas et al., 2014; Glenn et al., 2009; Whittingham et al., 2013).

The child's intellectual, emotional, and behavioral problems further increase the burden of caregivers and may negatively influence their quality of life and health (Carona et al., 2013; Glenn et al., 2009; Guyard et al., 2011). Carona et al. (2013) study parents of children with and without CP and conclude that an increased caregiving burden seemed to elicit a negative perception of social support, which in turn impaired the parent's psychological adjustment.

In addition to the behavioral problems, the presence of pain and sensory impairments in the child were also associated with a higher risk of clinical stress among parents of children with CP (Al-Gamal \& Long, 2013). Similar findings were identified in the investigated sample, with presence of health problems in the children influencing the occurrence of clinical stress among the caregivers.

The results of the present study point to the need to include caregivers in the protocols of the services made available to children with $\mathrm{CP}$. According to the literature, the efficacy of child-centered cared models is lower compared to ecological models, in which actions target the family system (Byrne et al., 2010; Carona et al., 2013).

Aiming at describing and investigating the presence of association of parental stress with perceived social support and the sociodemographic indicators of caregivers of children with CP from a capital city in Eastern Amazon, the present study established which specific aspects of these variables were related. In addition, it found that most participants had high levels of perceived social support, even when they parented with inadequate levels of stress.

The results of the present study are helpful for the development of strategies for the prevention and reduction of parental stress because they show which aspects of the investigated variables seem to have a more effective impact on the others, in addition to identifying risk and protective factors for caregivers. Moreover, the results suggest further topics relevant for the study of the targeted caregivers, such as the structure of their social support network and the quality of the support provided by spouses. Concerning the limitations of the present study, lack of knowledge of the population size did not make it possible to estimate the optimal number of individuals who should have been included in the study, in addition to the need for caution in the generalization of the results.

Given the panorama described here and the assumption that children are part of an integrated and dynamic system, it is important for future studies to seek to understand how the psychosocial profile of the families of children with $\mathrm{CP}$, parental stress, and social support associate in the various Amazonian settings.

\section{References}

Abidin, R. R. (1992). The determinants of parenting behavior. Journal of Clinical Child Psychology, 21(4), 407-412. doi:10.1207/s15374424jccp2104_12

Abidin, R. R. (1995). Parenting Stress Index. Odessa, FL: Psychological Assessment Resources.

Al-Gamal, E., \& Long, T. (2013). Psychological distress and perceived support among Jordanian parents living with a child with cerebral palsy: A cross-sectional study. Scandinavian Journal of Caring Sciences, 27(3), 624631. doi:10.1111/j.1471-6712.2012.01071.x

Byrne, M. B., Hurley, D. A., Daly, L., \& Cunningham, C. G. (2010). Health status of caregivers of children with cerebral palsy. Child: Care, Health and Development, 36(5), 696-702. doi:10.1111/j.1365-2214.2009.01047.x

Cans, C. (2000). Surveillance of cerebral palsy in Europe: A collaboration of cerebral palsy surveys and registers. Developmental Medicine \& Child Neurology, 42(12), 816-824. doi:10.1111/j.1469-8749.2000.tb00695.x

Carona, C., Crespo, C., \& Canavarro, M. C. (2013). Similarities amid the difference: Caregiving burden and adaptation outcomes in dyads of parents and their children with and without cerebral palsy. Research in Developmental Disabilities, 34(3), 882-893. doi:10.1016/j.ridd.2012.12.004

Dang, V. M., Colver, A., Dickinson, H. O., Marcelli, M., Michelsen, S. I., Parkes, J., . . Fauconnier, J. (2015). Predictors of participation of adolescents with cerebral palsy: A European multi-centre longitudinal study. Research in Developmental Disabilities, 36, 551-564. doi:10.1016/j.ridd.2014.10.043

Dantas, M. S. A., Pontes, J. F., Assis, W. D., \& Collet, N. (2012). Facilidades e dificuldades da família no cuidado à criança com paralisia cerebral [Family's abilities and difficulties in caring for children with cerebral palsy]. Revista Gaúcha de Enfermagem, 33(3), 73-80. doi:10.1590/S1983-14472012000300010

Freitas, P. M., Rocha, C. M., \& Haase, V. G. (2014). Análise 
dos preditores do estado psicológico das mães de crianças com paralisia cerebral [Analysis of predictors of psychological status of mothers of children with cerebral palsy]. Estudos e Pesquisas em Psicologia, 14(2), 453473. Retrieved from http://pepsic.bvsalud.org/pdf/epp/ v14n2/v14n2a05.pdf

Glenn, S., Cunningham, C., Poole, H., Reeves, D., \& Weindling, M. (2009). Maternal parenting stress and its correlates in families with a young child with cerebral palsy. Child: Care, Health and Development, 35(1), 7178. doi:10.1111/j.1365-2214.2008.00891.x

Griep, R. H. (2003). Confiabilidade e validade de instrumentos de medida de rede social e de apoio social utilizados no estudo pró-saúde [Reliability and validity of measurement instruments of social network and social support used in the Estudo Pró-Saúde] (Doctoral dissertation). Retrieved from http://arca.icict.fiocruz.br/ bitstream/icict/4487/2/157.pdf

Guyard, A., Fauconnier, J., Mermet, M.-A., \& Cans, C. (2011). Impact sur les parents de la paralysie cérébrale chez l'enfant: Revue de la littérature [Impact on parents of cerebral palsy in children: A literature review]. Archives de Pédiatrie, 18(2), 204-214. doi:10.1016/j. arcped.2010.11.008

Hiratuka, E., Matsukura, T. S., \& Pfeifer, L. I. (2010). Cross-cultural adaptation of the Gross Motor Function Classification System into Brazilian-Portuguese (GMFCS). Brazilian Journal of Physical Therapy, 14(6), 537-544. doi:10.1590/S1413-35552010000600013

Infantosi, A. F. C., Costa, J. C. G. D., \& Almeida, R. M. V. R. (2014). Análise de correspondência: Bases teóricas na interpretação de dados categóricos em ciências da saúde [Correspondence analysis: A theoretical basis for categorical data interpretation in health sciences]. Cadernos de Saúde Pública, 30(3), 473-486. doi:10.1590/0102-311X00128513

Lima, M. B. S., Afonso, T., \& Silva, S. C. (2015). Cuidadores primários de crianças com autismo na Amazônia: Suporte social e estresse [Primary caregivers of autistic children in the Amazon]. Apae Ciência, 2(1), 21-36. Retrieved from http://apaeciencia.org.br/index.php/revista/article/ view/62/30

Minetto, M. F. J. (2010). Práticas educativas parentais, crenças parentais, estresse parental e funcionamento familiar de pais de crianças com desenvolvimento típico e atípico [Parenting practices, parental beliefs, parental stress and family functioning of parents of children with typical and atypical development] (Doctoral dissertation). Retrieved from https://repositorio.ufsc.br/ xmlui/handle/123456789/94159

Oliveira, F. L., \& Dounis, A. B, (2012). As alterações na dinâmica familiar diante do diagnóstico da criança com paralisia cerebral: Estado da arte [Changes in family dynamics before the diagnosis of cerebral palsy child: State of the Art]. Revista de Psicologia, 3(1), 18-27. Retrieved from http://www.periodicos.ufc.br/index.php/ psicologiaufc/article/view/101/100
Pfeifer, L. I., Silva, D. B. R., Lopes, P. B., Matsukura, T. S., Santos, J. L. F., \& Pinto, M. P. P. (2014). Social support provided to caregivers of children with cerebral palsy. Child: Care, Health and Development, 40(3), 363-369. doi:10.1111/cch.12077

Polita, N. B., \& Tacla, M. T. G. M. (2014). Rede e apoio social às famílias de crianças com paralisia cerebral [Network and social support to families of children with cerebral palsy]. Escola Anna Nery, 18(1), 75-81. doi:10.5935/1414-8145.20140011

Ribeiro, M. F. M., Sousa, A. L. L., Vandenberghe, L., \& Porto, C. C. (2014). Parental stress in mothers of children and adolescents with cerebral palsy. Revista Latino-Americana de Enfermagem, 22(3), 440-447. doi:10.1590/0104-1169.3409.2435

Rodriguez, M. S., \& Cohen, S. (1998). Social support. In H. Friedman (Ed.), Encyclopedia of mental health (Vol. 3, pp. 535-544). New York, NY: Academic Press. Retrieved from http://www.psy.cmu.edu/ scohen/socsupchap98. pdf

Russell, D., Rosenbaum, P. L., Avery, L. M., \& Lane, M. (2011). Medida da Função Motora Grossa GMFM-66 \& GMFM-88: Manual do usuário [Gross motor function measure (GMFM-66 and GMFM-88) user's manual] (S. T. Cyrillo \& M. C. S. Galvão, Trans.). São Paulo, SP: Memnon.

Sherbourne, C. D., \& Stewart, A. L. (1991). The MOS social support survey. Social Science \& Medicine, 32(6), $705-$ 714.

Whittingham, K., Wee, D., Sanders, M. R., \& Boyd, R. (2013). Predictors of psychological adjustment, experienced parenting burden and chronic sorrow symptoms in parents of children with cerebral palsy. Child: Care, Health and Development, 39(3), 366-373. doi:10.1111/ j.1365-2214.2012.01396.x

Mayara Barbosa Sindeaux Lima is a Psychologist at the Universidade Federal do Sul e Sudeste do Pará and Ph.D. candidate in the Graduate Program in Theory and Behavior Research at the Universidade Federal do Pará.

Vagner dos Santos Cardoso is a Psychologist at the Universidade Federal do Pará.

Simone Souza da Costa Silva is a Professor at the Universidade Federal do Pará.

Received: Apr. 28, 2015

1st Revision: Sep. 9, 2015

Approved: Oct. 27, 2015

How to cite this article:

Lima, M. B. S., Cardoso, V. S., \& Silva, S. S. C. (2016). Parental stress and social support of caregivers of cerebral palsy children. Paidéia (Ribeirão Preto), 26(64), 207-214. doi:10.1590/1982-43272664201608 